\title{
Comparing intracerebral hemorrhages associated with direct oral anticoagulants or warfarin
}

Ryota Kurogi, MD, Kunihiro Nishimura, MD, PhD, Michikazu Nakai, PhD, Akiko Kada, MPH, Satoru Kamitani, MD, PhD, Jyoji Nakagawara, MD, PhD, Kazunori Toyoda, MD, PhD, Kuniaki Ogasawara, MD, PhD, Junichi Ono, MD, PhD, Yoshiaki Shiokawa, MD, PhD, Toru Aruga, MD, PhD, Shigeru Miyachi, MD, PhD, Izumi Nagata, MD, PhD, Shinya Matsuda, MD, PhD, Shinichi Yoshimura, MD, PhD, Kazuo Okuchi, MD, PhD, Akifumi Suzuki, MD, PhD, Fumiaki Nakamura, MD, PhD, Daisuke Onozuka, PhD, Keisuke Ido, MD, Ai Kurogi, MD, Nobutaka Mukae, MD, PhD, Ataru Nishimura, MD, PhD, Koichi Arimura, MD, PhD, Takanari Kitazono, MD, PhD, Akihito Hagihara, DMSc, MPH, and Koji lihara, MD, PhD, J-ASPECT Study Collaborators

Neurology ${ }^{\circledR}$ 2018;90:e1143-e1149. doi:10.1212/WNL.0000000000005207

\section{Abstract \\ Objectives}

This cross-sectional survey explored the characteristics and outcomes of direct oral anticoagulant (DOAC)-associated nontraumatic intracerebral hemorrhages (ICHs) by analyzing a large nationwide Japanese discharge database.

\section{Methods}

We analyzed data from 2,245 patients who experienced ICHs while taking anticoagulants (DOAC: 227; warfarin: 2,018) and were urgently hospitalized at 621 institutions in Japan between April 2010 and March 2015. We compared the DOAC- and warfarin-treated patients based on their backgrounds, ICH severities, antiplatelet therapies at admission, hematoma removal surgeries, reversal agents, mortality rates, and modified Rankin Scale scores at discharge.

\section{Results}

DOAC-associated ICHs were less likely to cause moderately or severely impaired consciousness (DOAC-associated ICHs: 31.3\%; warfarin-associated ICHs: $39.4 \% ; p=0.002$ ) or require surgical removal (DOAC-associated ICHs: 5.3\%; warfarin-associated ICHs: $9.9 \%$; $p=0.024$ ) in the univariate analysis. Propensity score analysis revealed that patients with DOAC-associated ICHs also exhibited lower mortality rates within 1 day (odds ratio [OR] 4.96, $p=0.005$ ), within 7 days (OR 2.29, $p=0.037$ ), and during hospitalization (OR 1.96, $p=0.039$ ).

\section{Conclusions}

This nationwide study revealed that DOAC-treated patients had less severe ICHs and lower mortality rates than did warfarin-treated patients, probably due to milder hemorrhages at admission and lower hematoma expansion frequencies.

\author{
Correspondence \\ Dr. lihara \\ kiihara@ns.med.kyushu-u. \\ ac.jp
}

\footnotetext{
From the Departments of Neurosurgery (R.K., K. Ido, A. Kurogi, N.M., A.N., K.A., K. lihara), Health Communication (D.O., A.H.), and Medicine and Clinical Science (T.K.), Graduate School of Medical Sciences, Kyushu University; Department of Neuroendovascular Surgery (R.K.), National Hospital Organization, Clinical Research Institute, Kyushu Medical Center, Fukuoka; Department of Statistics and Data Analysis, Center for Cerebral and Cardiovascular Disease Information (K.N., M.N.), Integrative Stroke Imaging Centre (I.N.), and Department of Cerebrovascular Medicine (K.T.), National Cerebral and Cardiovascular Center, Suita; Department of Clinical Trials and Research (A. Kada), National Hospital Organization, Nagoya Medical Center; Division of Health Services Research (S.K.), Center for Cancer Control and Information Services, National Cancer Center, Tokyo; Department of Neurosurgery (K. Ogasawara), Iwate Medical University, Morioka; Department of Neurosurgery (J.O.), Sanmu Medical Center; Department of Neurosurgery (Y.S.), Kyorin University, Mitaka; Department of Emergency and Critical Care Medicine (T.A.), Showa University Hospital, Shinagawa; Department of Neurosurgery (S. Miyachi), Osaka Medical College, Takatsuki; Department of Neurosurgery (I.N.), Kokura Memorial Hospital; Department of Preventive Medicine and Community Health (S. Matsuda), School of Medicine, University of Occupational and Environmental Health, Kitakyushu; Department of Neurosurgery (S.Y.), Hyogo College of Medicine, Nishinomiya; Department of Emergency and Critical Care Medicine (K. Okuchi), Nara Medical University, Kashihara; Department of Surgical Neurology (A.S.), Research Institute for Brain and Blood Vessels, Akita; and Division of Data Management Center for Cardiovascular Disease Information (F.N.), National Cerebral Cardiovascular Disease Information, Suita, Japan.

Go to Neurology.org/N for full disclosures. Funding information and disclosures deemed relevant by the authors, if any, are provided at the end of the article.
} 


\section{Glossary}

AF $=$ atrial fibrillation; DOAC $=$ direct oral anticoagulant DPC $=$ Diagnosis Procedure Combination; FFP $=$ fresh frozen plasma; ICD-10 = International Classification of Diseases-10; ICH = intracerebral hemorrhage; JCS = Japan Coma Scale; $\mathbf{m R S}=$ modified Rankin Scale; OR = odds ratio; PCC = prothrombin complex; PT-INR = prothrombin time-international normalized ratio.

Clinical trials have shown that 4 direct oral anticoagulants (DOACs) - dabigatran, rivaroxaban, apixaban, and edoxaban-are as efficacious and safe as warfarin for stroke prevention in patients with atrial fibrillation $(\mathrm{AF}) .^{1}$ In randomized clinical trials with strict indication criteria, DOACtreated patients are reportedly at lower risk for hemorrhagic strokes than are warfarin-treated patients. ${ }^{1}$ Mortality rates were similar among patients randomly prescribed either DOAC or warfarin according to a secondary analysis of intracerebral hemorrhages (ICHs) occurring in the Randomized Evaluation of Long-Term Anticoagulation Therapy (RE-LY) trial ${ }^{2}$ and the Rivaroxaban Once Daily Oral Direct Factor Xa Inhibition Compared With Vitamin K Antagonism for Prevention of Stroke and Embolism Trial in Atrial Fibrillation. ${ }^{3}$ However, because those trials featured very strict inclusion criteria, these results cannot be generalized to all patients with DOAC- or warfarin-associated ICHs. Notably, in clinical practice of stroke prevention in AF, stroke outcomes can depend on various patient baseline characteristics, suboptimal dosage, and oral anticoagulant therapy adherence. ${ }^{4}$ However, few studies have compared the characteristics and outcomes of DOAC- and warfarin-associated ICHs in clinical practice. Because DOACs are used liberally in clinical practice, we expect that the incidence of DOACassociated ICHs will increase in coming years. ${ }^{5}$ We therefore aimed to compare the characteristics and outcomes of patients with DOAC- and warfarin-associated ICHs in clinical practice in Japan using a nationwide Diagnosis Procedure Combination (DPC) database.

\section{Methods}

\section{Standard protocol approvals, registrations, and patient consents}

This study was approved by the Kyushu University Institutional Review Board, which waived the requirement for individual informed consent.

\section{The DPC database}

The DPC is a mixed-case patient classification system that was launched in 2002 by the Japanese Ministry of Health, Labour and Welfare and is linked with a hospital financing system. ${ }^{6} \mathrm{By}$ 2015, the DPC system had been adopted by an estimated 1,580 acute care hospitals, representing approximately half of all Japanese hospital beds and encompassing a wide variety of centers, including rural and urban, academic and nonacademic, and small and large hospitals. ${ }^{7}$ The DPC database includes data about all patients admitted to participating hospitals, including each patient's profile (e.g., age, sex); principal diagnoses and comorbidities at admission (both coded by the International Classification of Diseases and Injuries, 10th revision); complications after admission (coded similarly); procedures including surgeries, medications, and devices used during hospitalization; length of stay; discharge status; and medical expense. ${ }^{8}$ The J-ASPECT study group has analyzed the DPC database to gain new clinical insights, ${ }^{7,9-11}$ an approach we applied again for this cross-sectional survey.

\section{Sampling strategy}

Of the 1,369 training institutions certified by the Japan Neurosurgical Society, the Japanese Society of Neurology, and the Japan Stroke Society, 621 agreed to participate in the J-ASPECT study. We identified patients hospitalized for nontraumatic ICH in the deidentified discharge database using the ICD-10 diagnosis codes related to nontraumatic ICH (I61.0-9, I62.0-1, and I62.9). We further selected those patients who had been urgently hospitalized between April 1, 2010, and March 31,2015, and were receiving a DOAC or warfarin before admission. We then extracted data about age and sex; comorbidities on admission, including those based on Charlson scores ${ }^{12}$; level of consciousness on admission according to the Japan Coma Scale (JCS), the most widely used grading scale for impaired consciousness in Japan (table e-1, links.lww.com/WNL/A284) $)^{7,9,13}$; concurrent preadmission use of antiplatelet drugs including aspirin, clopidogrel, ticlopidine, cilostazol, sarpogrelate, and prasugrel; hematoma removal with craniotomy, endoscopic surgery, or stereotactic aspiration; CSF drainage coded with Japanese original K-codes; use of reversal agents including vitamin $\mathrm{K}$, prothrombin complex (PCC) concentrate, and fresh frozen plasma (FFP); length of hospital stay; mortality; and modified Rankin Scale (mRS) score at discharge. Patients with missing data were excluded from this survey.

\section{Statistical analysis}

We compared the characteristics of DOAC- and warfarinassociated ICHs using Wilcoxon rank sum tests for continuous variables and $\chi^{2}$ tests for categorical variables. Multivariable analysis was undertaken to estimate the 2 groups' odds ratios (ORs) for mortality rates within 1 day, within 7 days, and during hospitalization and for discharge mRS scores in the 0-3 (good functional outcome) or 4-6 (poor functional outcome) ranges. The ORs were adjusted for sex, age, comorbidities, admission JCS scores, concurrent antiplatelet therapies, and treatment with surgery or reversal agents. We also estimated ORs for outcomes after 1:1 propensity score matching to account for between-group 
differences in baseline characteristics. To match patients, we used an automated matching procedure in STATA (STATA Corp., College Station, TX) that randomly selected a DOACtreated patient and a warfarin-treated patient within a propensity score caliper of \pm 0.01 . Successfully matched pairs were removed, and the procedure was repeated until all patients were matched or until no further matches were available within the caliper. Propensity scores for warfarinassociated outcomes were estimated using a probit model in which the independent variables were sex, age, comorbidities, admission JCS scores, concurrent antiplatelet therapy, and treatment with surgery or reversal agents. The interaction between usage of DOAC and usage of reversal agents for $\mathrm{ICH}$ removal surgeries was examined. The analyses were performed using JMP 11.0 (SAS Institute, Cary, NC), SAS 9.3 (SAS Institute), STATA 12, and SPSS 12 (IBM, Armonk, $\mathrm{NY}$ ). We defined statistical significance as $p<0.05$.

\section{Results}

\section{Patient demographics}

We identified 2,245 patients with DOAC- or warfarinassociated ICHs (DOAC: 227; warfarin: 2,018). The percentages of DOAC-treated patients in each year from 2010 to 2014 were $0 \%, 0.4 \%, 3.8 \%, 9.6 \%$, and $21.4 \%$, respectively. The proportions of dabigatran, rivaroxaban, apixaban, and edoxaban among DOAC-associated cases were 23.8\%, 57.8\%, $18.5 \%$, and $0 \%$, respectively.

Table 1 shows the characteristics of patients with DOAC- and warfarin-associated ICHs. No significant between-group differences were noted for age (mean age in years: DOAC, 74.4; warfarin, 74.2); comorbidities such as Charlson scores (mean: $4.9,5.0)$, hypertension $(56.4 \%, 53.0 \%)$, diabetes mellitus (22.5\%, $22.0 \%)$, or hyperlipidemia $(12.3 \%, 12.0 \%)$; or median lengths of hospital stays (median days: 18.0, 18.0). The DOAC-treated group had a greater proportion of men $(75.3 \%, 65.1 \% ; p=0.002)$ and smaller proportion of JCS 2and 3-digit codes (moderately or severely impaired consciousness, respectively) (31.3\%, 39.4\%; $p=0.002)$. Concurrent use of antiplatelet drugs was more frequent among warfarin-treated patients $(25.1 \%, 40.1 \% ; p<0.001)$. Overall usage rates for reversal agents, especially PCC, were quite low for both warfarin- and DOAC-treated patients. The DOAC-treated patients were less likely to be given vitamin $\mathrm{K}$ $(2.6 \%, 63.1 \% ; p<0.001)$ or FFP $(4.9 \%, 11.7 \% ; p<0.001)$; tended to be given PCC $(3.1 \%, 5.8 \% ; p=0.094)$, the most effective early reversal agent for warfarin; and were less likely to require ICH removal surgeries $(5.3 \%, 9.9 \%$; $p=0.024)$.

Considering the lack of specific antidotes for DOACs during the study period, we further analyzed the relationships between the frequency of ICH removal surgeries and the use of vitamin $\mathrm{K}, \mathrm{FFP}$, or PCC in warfarin- and DOAC-treated patients. We found that surgical ICH removal was associated with the use of vitamin $\mathrm{K}$ (presence, 13.6\%; absence, 3.6\%;
Table 1 Characteristics of direct oral anticoagulant (DOAC) and warfarin-associated intracerebral hemorrhage $(\mathrm{ICH})$ patients

\begin{tabular}{|c|c|c|c|}
\hline & $\begin{array}{l}\text { DOAC, } \\
n=227\end{array}$ & $\begin{array}{l}\text { Warfarin, } \\
n=2,018\end{array}$ & $p$ Value \\
\hline \multicolumn{4}{|l|}{ Patients } \\
\hline Male, n (\%) & $171(75.3)$ & $1,314(65.1)$ & 0.002 \\
\hline Age, $y$, mean \pm SD & $74.4 \pm 8.5$ & $74.2 \pm 10.5$ & 0.737 \\
\hline \multicolumn{4}{|l|}{ Comorbidities } \\
\hline Charlson score, mean, $\mathbf{n} \pm \mathrm{SD}$ & $4.9 \pm 1.4$ & $5.0 \pm 1.6$ & 0.172 \\
\hline Hypertension, n (\%) & $128(56.4)$ & $1,070(53.0)$ & 0.335 \\
\hline Diabetes mellitus, n (\%) & $51(22.5)$ & $443(22.0)$ & 0.859 \\
\hline Hyperlipidemia, n (\%) & $28(12.3)$ & $242(12.0)$ & 0.880 \\
\hline JCS score on admission & & & 0.002 \\
\hline 0- or 1-digit code, $\mathbf{n}(\%)$ & $156(68.7)$ & $1,224(60.7)$ & \\
\hline 2- or 3-digit code, n (\%) & $71(31.3)$ & $794(39.4)$ & \\
\hline $\begin{array}{l}\text { Concurrent antiplatelet } \\
\text { therapy, n (\%) }\end{array}$ & $57(25.1)$ & $810(40.1)$ & $<0.001$ \\
\hline
\end{tabular}

\begin{tabular}{|c|c|c|c|}
\hline \multicolumn{4}{|l|}{ Treatment/surgery } \\
\hline ICH removal, n (\%) & $12(5.3)$ & $200(9.9)$ & 0.024 \\
\hline External CSF drainage, $\mathrm{n}(\%)$ & $7(3.1)$ & $77(3.8)$ & 0.582 \\
\hline \multicolumn{4}{|l|}{ Treatment/reversal agent } \\
\hline Vitamin K, n (\%) & $6(2.6)$ & $1,273(63.1)$ & $<0.001$ \\
\hline PCC, n (\%) & $7(3.1)$ & $116(5.8)$ & 0.094 \\
\hline FFP, n (\%) & $11(4.9)$ & $236(11.7)$ & 0.002 \\
\hline $\begin{array}{l}\text { Length of hospital stay, } \\
\text { d, median } \pm \text { SD }\end{array}$ & $18 \pm 26.1$ & $18 \pm 27.6$ & 0.684 \\
\hline
\end{tabular}

Abbreviations: FFP = fresh frozen plasma; PCC = prothrombin complex concentrate.

$p<0.001$ ), FFP (presence, 47.9\%; absence, $4.9 \%$; $p<0.001$ ), or PCC (presence, $31.0 \%$; absence, $8.6 \%$; $p<0.001$ ) in patients with warfarin-associated ICHs, whereas no significant associations were observed for the use of vitamin $\mathrm{K}$ (presence, $0 \%$; absence, $5.3 \%$; $p=0.558$ ), FFP (presence, 9.1\%; absence, $5.1 \%$; $p=0.563$ ), or PCC (presence, $14.3 \%$; absence, $5.0 \%$; $p=0.280)$ in patients with DOAC-associated ICHs. After adjusting for the use of vitamin K, PCC, or FFP, the DOACand warfarin-treated groups exhibited no significant difference in ORs for ICH removal surgeries (OR 1.21, $p=0.608$ ), but the interaction between usage of DOAC and usage of reversal agents for ICH removal surgeries was marginally significant $(p=0.062)$ (table e-2, links.lww.com/WNL/A284). This suggested that warfarin vs DOAC tends to show different effect on ICH removal surgeries within the group based on usage of reversal agents. Table e-3 shows the hemorrhage locations of DOAC- and warfarin-associated ICHs obtained from DPC data representing $68.9 \%$ of the study cases. These 
Table 2 Outcomes of direct oral anticoagulant (DOAC) and warfarin-associated intracerebral hemorrhage patients

\begin{tabular}{llll}
\hline & $\begin{array}{l}\text { DOAC, } \\
\mathbf{n = 2 2 7}\end{array}$ & $\begin{array}{l}\text { Warfarin, } \\
\mathbf{n = 2 , 0 1 8}\end{array}$ & p Value \\
\hline Mortality within 1 day, $\mathbf{n}(\%)$ & $6(2.6)$ & $131(6.5)$ & 0.022 \\
\hline Mortality within 7 days, $\mathbf{n}(\%)$ & $27(11.9)$ & $368(18.2)$ & 0.017 \\
\hline In-hospital mortality, $\mathbf{n}(\%)$ & $40(17.6)$ & $510(25.3)$ & 0.011 \\
\hline Discharge mRS, mean \pm SD & $3.30 \pm 1.95$ & $3.50 \pm 2.04$ & 0.158 \\
\hline Discharge mRS 4-6, n (\%) & $119(52.4)$ & $1111(55.1)$ & 0.45 \\
\hline
\end{tabular}

Abbreviation: $\mathrm{mRS}=$ modified Rankin Scale.

data suggest no significant between-group differences in hematoma locations.

Table 2 shows mortality rates and discharge mRS scores for the DOAC- and warfarin-treated patients. The warfarintreated patients exhibited higher mortality rates within 1 day $(2.6 \%, 6.5 \%$; $p=0.022)$, within 7 days $(11.9 \%, 18.2 \% ; p=$ $0.017)$, and during hospitalization $(17.6 \%, 25.3 \% ; p=0.011)$. There were no significant differences in mean discharge $\mathrm{mRS}$ scores $(3.30,3.50)$ or the proportion of discharge $\mathrm{mRS}$ scores of $4-6(52.4 \%, 55.1 \%)$.

Table 3 shows the 2 groups' ORs for mortality within 1 day, within 7 days, and during hospitalization and for discharge mRS scores of 4-6 after adjusting for sex, age, comorbidities, admission JCS scores, concurrent antiplatelet therapy, and treatment with surgery or reversal agents. The warfarintreated patients exhibited higher ORs for mortality within 1 day (OR 4.06, $p<0.001$ ), within 7 days (OR 1.96, $p=0.012$ ), and during hospitalization (OR 1.60, $p=0.041$ ). The 2

Table 3 Odds ratios (ORs) of mortality within 1 day, 7 days, and during hospitalization, and modified Rankin Scale (mRS) 4-6 at discharge in warfarinassociated intracerebral hemorrhage patients compared with direct oral anticoagulant-associated patients after adjusting for sex, age, comorbidities, Japan Coma Scale on admission, concurrent antiplatelet therapy, and treatment (surgery and reversal agent)

\begin{tabular}{llll}
\hline & OR & $95 \% \mathrm{Cl}$ & $\boldsymbol{p}$ Value \\
\hline Mortality within 1 day & 4.06 & $1.78-10.99$ & $<0.001$ \\
\hline Mortality within 7 days & 1.96 & $1.15-3.39$ & 0.012 \\
\hline In-hospital mortality & 1.6 & $1.02-2.56$ & 0.041 \\
\hline Discharge mRS 4-6 & 0.79 & $0.56-1.12$ & 0.181 \\
\hline
\end{tabular}

Abbreviation: $\mathrm{Cl}=$ confidence interval.
Table 4 Odds ratios (ORs) of mortality within 1 day, 7 days, and during hospitalization, and modified Rankin Scale (mRS) 4-6 at discharge in warfarinassociated intracerebral hemorrhage patients compared with direct oral anticoagulant-associated patients after matching by propensity score

\begin{tabular}{llll}
\hline & OR & $95 \% \mathrm{CI}$ & $\boldsymbol{p}$ Value \\
\hline Mortality within 1 day & 4.96 & $1.61-15.25$ & 0.005 \\
\hline Mortality within 7 days & 2.29 & $1.05-5.00$ & 0.037 \\
\hline In-hospital mortality & 1.96 & $1.03-3.72$ & 0.039 \\
\hline Discharge mRS 4-6 & 0.76 & $0.48-1.20$ & 0.246 \\
\hline
\end{tabular}

Abbreviation: $\mathrm{Cl}=$ confidence interval.

groups' ORs for discharge mRS scores of 4-6 were not significantly different.

\section{Propensity score analysis}

Table 4 shows the 2 groups' ORs for mortality within 1 day, within 7 days, and during hospitalization and for discharge mRS score of 4-6 after matching patients by propensity scores $(\mathrm{n}=221$ vs $\mathrm{n}=221)$. Table e-4 (links.lww.com/WNL/A284) shows the propensity score-adjusted data for sex, age, comorbidities, admission JCS scores, concurrent antiplatelet therapies, and treatment with surgery or reversal agents. The warfarin-treated patients exhibited higher ORs for mortality within 1 day (OR 4.96, $p=0.005$ ), within 7 days (OR 2.29, $p=0.037$ ), and during hospitalization (OR 1.96, $p=0.039$ ). The 2 groups did not significantly differ in ORs for discharge mRS scores of 4-6.

We also applied propensity score analysis to the outcomes for DOAC- and warfarin-treated patients. The propensity score-matched patients tended to have similar characteristics. Compared to the warfarin-treated patients, the dabigatran$(\mathrm{n}=51$ vs $\mathrm{n}=51)$ and apixaban-treated patients $(\mathrm{n}=42$ vs $\mathrm{n}=$ 42) did not exhibit significantly different mortality rates or likelihoods of discharge mRS scores of 4-6 (table e-5 and e-6). The rivaroxaban-treated patients $(n=127$ vs $n=127)$, however, exhibited lower mortality rates within 1 day $(\mathrm{OR}=$ 11.22, $p=0.023$ ), though this was not the case for mortality rates within 7 days or during hospitalization or for the likelihood of discharge mRS scores of 4-6 (table e-7).

\section{Discussion}

Our objective in this study was to compare the characteristics and outcomes of DOAC- and warfarin-associated ICHs in clinical practice. Administrative databases of hospital admissions are increasingly used for clinical outcome studies. Despite several limitations, using nationwide databases provides large sample sizes and produces more generalizable results than randomized trials because it eliminates potential 
selection and referral biases. ${ }^{10}$ The J-ASPECT study is the first nationwide survey on the clinical practice of stroke care in Japan that uses data obtained from hospitals subject to the DPC-based payment system. ${ }^{10}$ This study had a larger sample of clinical patients than did previous reports comparing DOAC- and warfarin-associated ICHs. ${ }^{5,14-16}$ Furthermore, we added a propensity score analysis and a multivariable analysis to compare the clinical outcomes from warfarinassociated ICHs to DOAC-associated ICHs collectively and the ICHs associated with each individual DOAC separately, with adjustments for key variables such as concurrent antiplatelet therapies ${ }^{17-19}$ and reversal agents. ${ }^{17,20,21}$ Compared to the warfarin-associated ICHs, the DOAC-associated ICHs were of lesser severity in the univariate analysis and were associated with lower in-hospital mortality after matching with propensity scores derived from clinical data. Our results are therefore robust and provide important clinical insights into optimizing oral anticoagulation therapy for stroke prevention in patients with $\mathrm{AF}$.

Few studies have compared the clinical and radiologic characteristics and outcomes of DOAC- and warfarin-associated ICHs, ${ }^{5,15,16}$ and they have featured small sample sizes of DOAC-associated ICHs. ${ }^{5,15,16}$ These studies found that patients with DOAC-associated ICHs had lower mortality rates, ${ }^{15}$ smaller hematomas, ${ }^{5,15,16}$ and less hematoma expansion. ${ }^{5,15}$ In a case series study of DOAC-associated $\mathrm{ICHs},{ }^{22,23}$ none showed small hematoma expansion. In animal model studies, dabigatran treatment results in lower ICH volumes and less hematoma expansion than does warfarin treatment. ${ }^{24,25}$ These reports support our observation that DOAC-associated ICHs were less severe and were associated with lower mortality rates.

Several reports have explored the mechanisms behind DOAC-associated ICHs having smaller volumes and less hematoma expansion than warfarin-associated ICHs. ${ }^{5,22,23,26}$ Complexes of tissue factor VII are essential for the first reaction in the extrinsic coagulation cascade. ${ }^{27}$ Warfarin inhibits vitamin $\mathrm{K}$-dependent coagulation proteins II, VII, IX, and X, while DOAC never inhibits factor VII function. ${ }^{28}$ Furthermore, DOAC half-lives are shorter than warfarin's half-life. ${ }^{28}$

Our univariate analysis showed that warfarin-treated patients were more likely to undergo ICH removal surgeries, but this difference did not survive adjustments for the use of reversal agents. However, it is difficult to interpret these contradictory results, because the interaction between ICH removal surgeries and reversal agent usage was marginally significant. The appropriateness of surgery for most patients with spontaneous ICHs remains controversial, but it is recommended for patients with cerebellar hemorrhages who are deteriorating neurologically or who have brainstem compression or hydrocephalus from ventricular obstruction. ${ }^{29}$ Initial hematoma volume is the most powerful predictor of neurologic deterioration, functional outcome, and mortality in both spontaneous and oral anticoagulant-associated ICHs, whereas the level of consciousness is highly predictive in infratentorial ICHs. ${ }^{30,31}$ The proportion of cerebellar hemorrhages in this study is notably similar to that of a previous Japanese study that showed that prior treatment with antiplatelets, warfarin, or both is predictive of cerebellar hemorrhages, hematoma enlargement, and early death in Japanese patients with ICHs. ${ }^{32}$ In line with previous studies comparing patients with DOAC- and warfarin-associated ICHs, ${ }^{5,16,33}$ we found no significant between-group difference in ICH locations. However, the DPC data excluded information about the eloquence of the $\mathrm{ICH}$ lesions and the size and expansion of hematomas. In terms of lesion eloquence, our study revealed that DOAC-associated ICHs were associated with similar functional outcomes. Given the strong effect of initial hemorrhage locations on functional outcomes following DOAC- and warfarin-associated ICHs regardless of hematoma size or expansion, ${ }^{34}$ we doubt there were any betweengroup differences in the proportions of eloquent area ICHs in our sample. Therefore, the localization and eloquence of the lesions does not seem to explain the different rates of $\mathrm{ICH}$ removal surgeries for our warfarin- and DOAC-treated groups. Regarding the size and expansion of hematomas, past studies ${ }^{5,15-20}$ have shown that DOAC-associated ICHs have smaller hemorrhage volumes and lower chances of hematoma expansion, which may explain our observation. A previous study comparing the effects of different reversal agents on hematoma growth and outcomes in patients with warfarin-related ICHs found that PCC was associated with a reduced incidence and extent of hematoma growth relative to FFP and vitamin $\mathrm{K}^{35}$ The present study, however, revealed that reversal strategies are not as widely applied in clinical practice in Japan as they are in Western countries, ${ }^{16,33}$ with PCC being used less frequently for warfarin-treated patients and specific reversal agents for DOACs such as idarucizumab being unavailable during the study period. ${ }^{17,20,21}$ Despite such overall low usage, more frequent usage in specific scenarios, especially PCC for patients who underwent removal surgeries for warfarin-associated ICHs, suggests that such strategies are mainly indicated for patients with large initial hematoma volumes and a high risk of neurologic deterioration. Furthermore, our study revealed that patients with warfarinassociated ICHs who were treated with reversal agents were more likely to require removal surgeries. This suggests that among patients with warfarin-associated ICHs, those who require surgical removal of large ICHs are more likely to use reversal agents.

Despite the release of DOACs, issues with warfarin such as overuse for low-risk patients and underuse for high-risk patients persist, as does discordance between guidelines and clinical practice. Our results are inconsistent with those of comparative studies of DOAC- or warfarin-associated ICHs in clinical settings in Western countries. ${ }^{5,14,33}$ Alonso et al. ${ }^{14}$ found no significant medication-related differences in mortality for any type of intracranial hemorrhage (intracerebral, subdural, or subarachnoid). However, the results of subtype analyses should be interpreted cautiously because of imprecise 
estimates and small numbers. ${ }^{14}$ Considering the prognosis differences between ICH subtypes, we focused on 227 DOAC-associated ICHs while excluding other hemorrhage subtypes. In contrast, the Registry of Acute Stroke Under New Oral Anticoagulants ${ }^{33}$ showed that DOAC-associated ICHs were associated with higher mortality rates, more unfavorable outcomes, and greater hematoma expansion frequencies. However, these conclusions were derived from comparisons with both warfarin-associated ICHs in that study and those in previously published retrospective observational studies. Another comparative study showed slightly higher mortality rates in patients with DOAC-associated ICHs but did not adjust for confounding factors with multivariate analyses or propensity score matching. ${ }^{5}$ Another explanation for the disparity between our study and that of those 3 studies $^{5,14,33}$ may be the differences in patient ethnicity. The median case-fatality at 1 month for patients with ICHs is lower in Japan than in other countries, ${ }^{36}$ and there are slight differences in the efficacy and safety of DOACs and warfarin between Asian and non-Asian populations. ${ }^{37,38}$ Resolving these discrepancies will require multinational observational collaborative studies and randomized controlled trials comparing DOACs and warfarin.

Each DOAC exhibits a unique dose-dependent efficacy and safety profile. ${ }^{1}$ We therefore used propensity score analysis to separately compare the outcomes for each DOAC to those of warfarin. Compared to warfarin-treated patients, rivaroxabantreated patients exhibited significantly lower 1-day mortality rates, while dabigatran- and apixaban-treated patients did not. These differences may be explained by the sample sizes for each DOAC. In Japan, dabigatran, rivaroxaban, and apixaban were launched in March 2011, April 2012, and February 2013, respectively, and edoxaban was approved for additional indications in September 2014. The timing of these launches may account for the proportions of each DOAC in this study. Larger sample sizes are needed to compare the characteristics and outcomes of each DOAC with those of warfarin.

The DPC database lacks several types of data. First, the database does not include laboratory data. The prothrombin time-international normalized ratio (PT-INR) is a particularly important factor in assessing the influence of hemorrhagic stroke. ${ }^{17}$ In this respect, it is interesting to note that the Japanese Fushimi AF Registry reported that over $90 \%$ of patients had PT-INR values within the optimal range. ${ }^{39}$ Given this observation, it is unlikely that high PT-INR values alone could account for our observation of warfarin-associated ICHs being more severe, requiring removal more often, and being associated with higher mortality rates. Second, it does not contain vital signs data. Notably, a meta-analysis of 5 randomized controlled trials also showed that early intensive blood pressure reduction did not significantly reduce the mortality rate. ${ }^{40}$ Admittedly, these missing data are unmeasured confounders for this study, so there is a need for further research that combines DPC database information with laboratory and radiologic data.
Although end-of-life decisions are an important factor in mortality, we had no information about such decisions. Previous studies comparing patients with DOAC- and warfarin-associated ICHs revealed no between-group differences in end-of-life decisions and found that mortality due to end-of-life decisions was low (i.e., 6\%). ${ }^{5}$ In Japan, the proportion of end-of-life decisions is reportedly much lower than in other countries. ${ }^{41}$ Collectively, these facts lead us to suspect a minor effect of end-of-life decision on mortality in our patients.

This is the largest Japan-wide study of DOAC-associated ICHs in clinical practice, and it revealed that DOACassociated ICHs were less lethal than warfarin-associated ICHs, probably due to lower hemorrhage severity at admission and lower hematoma expansion frequencies.

\section{Author contributions}

Ryota Kurogi drafted the manuscript. Koji Iihara was involved in conceptualizing and designing the study and in obtaining funding. Jyoji Nakagawara, Kazunori Toyoda, Kuniaki Ogasawara, Junichi Ono, Yoshiaki Shiokawa, Toru Aruga, Shigeru Miyachi, Izumi Nagata, Shinya Matsuda, Shinichi Yoshimura, Kazuo Okuchi, and Akifumi Suzuki were involved in data acquisition. Ryota Kurogi, Kunihiro Nishimura, Michikazu Nakai, Akiko Kada, Satoru Kamitani, Daisuke Onozuka, Keisuke Ido, Ai Kurogi, Nobutaka Mukae, Ataru Nishimura, Koichi Arimura, Akihito Hagihara, and Koji Iihara were involved in analyzing and interpreting the data. Jyoji Nakagawara, Kazunori Toyoda, Kuniaki Ogasawara, Junichi Ono, Yoshiaki Shiokawa, Toru Aruga, Shigeru Miyachi, Izumi Nagata, Shinya Matsuda, Shinichi Yoshimura, Kazuo Okuchi, Akifumi Suzuki, Takanari Kitazono, and Koji Iihara were involved in study supervision.

\section{Acknowledgment}

The authors thank the J-ASPECT study collaborators for their contributions. The names of the 621 participating hospitals and their representatives are listed in the online-only data supplement. All contributors were involved in data collection. The authors also thank Drs. Manabu Hasegawa, Tomoatsu Tsuji, and Yasuhiro Nishijima for discussion, Profs. Takamasa Kayama and Nobuo Hashimoto for supervision of the collaboration with the Japan Neurosurgical Society, and Arisa Ishitoko for secretarial assistance.

\section{Study funding}

This work was supported by Grants-in-Aid from the Japanese Ministry of Health, Labour and Welfare and a KAKENHI grant (25293314; principal investigator: Koji Iihara) from the Japan Society for the Promotion of Science. This research is partially supported by the Practical Research Project for LifeStyle related Diseases including Cardiovascular Diseases and Diabetes Mellitus managed by the Japan Agency for Medical Research and Development. The funding sources had no role in the study design, data collection and analysis, manuscript preparation, or decision to publish. 


\section{Disclosure}

R. Kurogi reports no disclosures relevant to the manuscript. K. Nishimura reports receiving lecture fees from Bristol-Myers Squibb. M. Nakai, A. Kada, S. Kamitani, and J. Nakagawara report no disclosures relevant to the manuscript. K. Toyoda reports receiving honoraria for lectures from Bayer, DaiichiSankyo, Boehringer-Ingelheim, and Bristol-Myers Squibb. K. Ogasawara reports receiving grants from Nihon MediPhysics and Bristol-Myers Squibb. J. Ono, Y. Shiokawa, T. Aruga, and S. Miyachi report no disclosures relevant to the manuscript. I. Nagata reports receiving honoraria for lectures from Bristol-Myers Squibb. S. Matsuda reports receiving honoraria for lectures from Chugai Pharmaceutical. S. Yoshimura reports receiving grants from Shionogi \& Co., Terumo, Takeda, and Bristol-Meyers Squibb and honoraria for lectures from Mitsubishi Tanabe Pharma, Sanofi, Bristol-Myers Squibb, Boehringer-Ingelheim, Otsuka Pharmaceutical, Bayer, Daiichi Sankyo, and Pfizer. K. Okuchi reports no disclosures relevant to the manuscript. A. Suzuki is a member of the medical advisory committee to the Akita Pilot Study undertaken by Bayer. F. Nakamura reports receiving grants from Asahi Kasei. D. Onozuka, K. Ido, A. Kurogi, N. Mukae, A. Nishimura, and $\mathrm{K}$. Arimura report no disclosures relevant to the manuscript. T. Kitazono reports receiving speaker fees from Bayer Yakuhin and Daiichi Sankyo, consulting fees from Chugai Pharmaceutical, and grants from Mitsubishi Tanabe Pharma, Takeda Pharmaceutical, Eizai, Merck Sharp \& Dohme, Astellas Pharma, Daiichi Sankyo, and Chugai Pharmaceutical. A. Hagihara reports no disclosures relevant to the manuscript. K. Iihara reports receiving grants from Otsuka Pharmaceutical, Nihon Medi-Physics, and AstraZeneca. Go to Neurology.org/ $\mathrm{N}$ for full disclosures.

Received June 24, 2017. Accepted in final form December 27, 2017.

\section{References}

1. Chan NC, Paikin JS, Hirsh J, Lauw MN, Eikelboom JW, Ginsberg JS. New oral anticoagulants for stroke prevention in atrial fibrillation: impact of study design, double counting and unexpected findings on interpretation of study results and conclusions. Thromb Haemost 2014;111:798-807.

2. Hart RG, Diener HC, Yang S, et al. Intracranial hemorrhage in atrial fibrillation patients during anticoagulation with warfarin or dabigatran: the RE-LY trial. Stroke 2012;43:1511-1517.

3. Hankey GJ, Stevens SR, Piccini JP, et al. Intracranial hemorrhage among patients with atrial fibrillation anticoagulated with warfarin or rivaroxaban: the rivaroxaban once daily, oral, direct factor Xa inhibition compared with vitamin $\mathrm{K}$ antagonism for prevention of stroke and embolism trial in atrial fibrillation. Stroke 2014;45:1304-1312.

4. Nguyen E, White CM, Patel MR, et al. Doses of apixaban and rivaroxaban prescribed in real-world United States cardiology practices compared to registration trials. Curr Med Res Opin 2016;32:1277-1279.

5. von der Brelie C, Doukas A, Naumann R, et al. Clinical and radiological course of intracerebral haemorrhage associated with the new non-vitamin $\mathrm{K}$ anticoagulants. Acta Neurochir 2017;159:101-109.

6. Yasunaga H, Ide H, Imamura T, Ohe K. Impact of the Japanese Diagnosis Procedure Combination-based payment system on cardiovascular medicine-related costs. Int Heart J 2005;46:855-866.

7. Iihara K, Nishimura K, Kada A, et al. The impact of comprehensive stroke care capacity on the hospital volume of stroke interventions: a nationwide study in Japan: J-ASPECT study. J Stroke Cerebrovasc Dis 2014;23:1001-1018.

8. Nakamura K. Diagnosis Procedure Combination database would develop nationwide clinical research in Japan. Circ J 2016;80:2289-2290.

9. Iihara K, Nishimura K, Kada A, et al. Effects of comprehensive stroke care capabilities on in-hospital mortality of patients with ischemic and hemorrhagic stroke: J-ASPECT study. PLoS One 2014;9:e96819.

10. Nishimura A, Nishimura K, Kada A, Iihara K; J-ASPECT study group. Status and future perspectives of utilizing big data in neurosurgical and stroke research. Neurol Med Chir 2016;56:655-663.
11. Onozuka D, Hagihara A, Nishimura K, et al. Prehospital antiplatelet use and functional status on admission of patients with non-haemorrhagic moyamoya disease: a nationwide retrospective cohort study (J-ASPECT study). BMJ Open 2016;6:e009942.

12. Charlson ME, Pompei P, Ales KL, MacKenzie CR. A new method of classifying prognostic comorbidity in longitudinal studies: development and validation. J Chronic Dis 1987;40:373-383.

13. Shigematsu K, Nakano H, Watanabe Y. The eye response test alone is sufficient to predict stroke outcome: reintroduction of Japan Coma Scale: a cohort study. BMJ Open 2013;3:e002736.

14. Alonso A, Bengtson LG, MacLehose RF, Lutsey PL, Chen LY, Lakshminarayan K. Intracranial hemorrhage mortality in atrial fibrillation patients treated with dabigatran or warfarin. Stroke 2014;45:2286-2291.

15. Hagii J, Tomita H, Metoki N, et al. Characteristics of intracerebral hemorrhage during rivaroxaban treatment: comparison with those during warfarin. Stroke 2014;45: 2805-2807.

16. Wilson D, Charidimou A, Shakeshaft C, et al. Volume and functional outcome of intracerebral hemorrhage according to oral anticoagulant type. Neurology 2016;86:360-366.

17. Mittal MK, LacKamp A. Intracerebral hemorrhage: perihemorrhagic edema and secondary hematoma expansion: from bench work to ongoing controversies. Front Neurol 2016;7:210.

18. Oldgren J, Wallentin L, Alexander JH, et al. New oral anticoagulants in addition to single or dual antiplatelet therapy after an acute coronary syndrome: a systematic review and meta-analysis. Eur Heart J 2013;34:1670-1680.

19. Toyoda K, Yasaka M, Iwade K, et al. Dual antithrombotic therapy increases severe bleeding events in patients with stroke and cardiovascular disease: a prospective, multicenter, observational study. Stroke 2008;39:1740-1745.

20. Kaatz S, Kouides PA, Garcia DA, et al. Guidance on the emergent reversal of oral thrombin and factor Xa inhibitors. Am J Hematol 2012;87(suppl 1):S141-S145.

21. Pollack CV Jr. Managing bleeding in anticoagulated patients in the emergency care setting. J Emerg Med 2013;45:467-477.

22. Akiyama H, Uchino K, Hasegawa Y. Characteristics of symptomatic intracranial hemorrhage in patients receiving non-vitamin $\mathrm{K}$ antagonist oral anticoagulant therapy. PLoS One 2015; 10:e132900.

23. Komori M, Yasaka M, Kokuba K, et al. Intracranial hemorrhage during dabigatran treatment. Circ J 2014;78:1335-1341.

24. Lauer A, Cianchetti FA, Van Cott EM, et al. Anticoagulation with the oral direct thrombin inhibitor dabigatran does not enlarge hematoma volume in experimental intracerebral hemorrhage. Circulation 2011;124:1654-1662.

25. Won SY, Schlunk F, Dinkel J, et al. Imaging of contrast medium extravasation in anticoagulation-associated intracerebral hemorrhage with dual-energy computed tomography. Stroke 2013;44:2883-2890.

26. Tempaku A. Intracranial hemorrhage during administration of a novel oral anticoagulant. J Rural Med 2016;11:69-72.

27. Morrison SA, Jesty J. Tissue factor-dependent activation of tritium-labeled factor IX and factor X in human plasma. Blood 1984;63:1338-1347.

28. Ieko M, Naitoh S, Yoshida M, Takahashi N. Profiles of direct oral anticoagulants and clinical usage-dosage and dose regimen differences. J Intensive Care 2016;4:19.

29. Hemphill JC III, Greenberg SM, Anderson CS, et al. Guidelines for the management of spontaneous intracerebral hemorrhage: a guideline for healthcare professionals from the American Heart Association/American Stroke Association. Stroke 2015;46:2032-2060.

30. Berwaerts J, Dijkhuizen RS, Robb OJ, Webster J. Prediction of functional outcome and in-hospital mortality after admission with oral anticoagulant-related intracerebral hemorrhage. Stroke 2000;31:2558-2562.

31. Broderick JP, Brott TG, Duldner JE, Tomsick T, Huster G. Volume of intracerebral hemorrhage: a powerful and easy-to-use predictor of 30-day mortality. Stroke 1993; 24:987-993.

32. Toyoda K, Yasaka M, Nagata K, et al. Antithrombotic therapy influences location, enlargement, and mortality from intracerebral hemorrhage: The Bleeding with Antithrombotic Therapy (BAT) Retrospective Study. Cerebrovasc Dis 2009;27:151-159.

33. Purrucker JC, Haas K, Rizos T, et al. Early clinical and radiological course, management, and outcome of intracerebral hemorrhage related to new oral anticoagulants. JAMA Neurol 2016;73:169-177.

34. Rost NS, Smith EE, Chang Y, et al. Prediction of functional outcome in patients with primary intracerebral hemorrhage: the FUNC score. Stroke 2008;39:2304-2309.

35. Huttner HB, Schellinger PD, Hartmann M, et al. Hematoma growth and outcome in treated neurocritical care patients with intracerebral hemorrhage related to oral anticoagulant therapy: comparison of acute treatment strategies using vitamin $\mathrm{K}$, fresh frozen plasma, and prothrombin complex concentrates. Stroke 2006;37:1465-1470.

36. van Asch CJ, Luitse MJ, Rinkel GJ, van der Tweel I, Algra A, Klijn CJ. Incidence, case fatality, and functional outcome of intracerebral haemorrhage over time, according to age, sex, and ethnic origin: a systematic review and meta-analysis. Lancet Neurol 2010;9:167-176.

37. Senoo K, Lau YC, Dzeshka M, Lane D, Okumura K, Lip GY. Efficacy and safety of non-vitamin $\mathrm{K}$ antagonist oral anticoagulants vs. warfarin in Japanese patients with atrial fibrillation: meta-analysis. Circ J 2015;79:339-345.

38. Yasaka M, Lip GY. Stroke prevention in Asian patients with atrial fibrillation. Stroke 2014;45:1608-1609.

39. Akao M, Chun $\mathrm{YH}$, Esato $\mathrm{M}$, et al. Inappropriate use of oral anticoagulants for patients with atrial fibrillation. Circ J 2014;78:2166-2172.

40. Ma J, Li H, Liu Y, You C, Huang S, Ma L. Effects of intensive blood pressure lowering on intracerebral hemorrhage outcomes: a meta-analysis of randomized controlled trials. Turk Neurosurg 2015;25:544-551.

41. Makino J, Fujitani S, Twohig B, Krasnica S, Oropello J. End-of-life considerations in the ICU in Japan: ethical and legal perspectives. J Intensive Care 2014;2:9. 


\section{Comparing intracerebral hemorrhages associated with direct oral anticoagulants or warfarin}

Ryota Kurogi, MD, Kunihiro Nishimura, MD, PhD, Michikazu Nakai, PhD, Akiko Kada, MPH, Satoru Kamitani, MD, PhD, Jyoji Nakagawara, MD, PhD, Kazunori Toyoda, MD, PhD,

Kuniaki Ogasawara, MD, PhD, Junichi Ono, MD, PhD, Yoshiaki Shiokawa, MD, PhD, Toru Aruga, MD, PhD, Shigeru Miyachi, MD, PhD, Izumi Nagata, MD, PhD, Shinya Matsuda, MD, PhD, Shinichi Yoshimura, MD, PhD, Kazuo Okuchi, MD, PhD, Akifumi Suzuki, MD, PhD, Fumiaki Nakamura, MD, PhD, Daisuke Onozuka, PhD, Keisuke Ido, MD, Ai Kurogi, MD, Nobutaka Mukae, MD, PhD, Ataru Nishimura, MD, PhD, Koichi Arimura, MD, PhD, Takanari Kitazono, MD, PhD, Akihito Hagihara, DMSc, MPH, and Koji lihara, MD, PhD, J-ASPECT Study Collaborators

Cite as: Neurology ${ }^{\circledR}$ 2018;90:e1143-e1149. doi:10.1212/WNL.0000000000005207

\author{
Correspondence \\ Dr. lihara \\ kiihara@ns.med.kyushu-u. \\ ac.jp
}

\section{Study question}

How do outcomes for direct oral anticoagulant (DOAC)associated intracerebral hemorrhages (ICHs) compare to those for warfarin-associated ICHs?

\section{Summary answer}

DOAC-associated ICHs are less severe and are associated with lower mortality rates.

\section{What is known and what this paper adds}

Past studies reported that patients with DOAC-associated ICHs have lower mortality rates than patients with warfarinassociated ICHs do, but strict inclusion criteria limited the generalizability of their results. This study provides corroborating evidence obtained by analyzing the nationwide Japanese Diagnosis Procedure Combination (DPC) clinical practice database.

\section{Participants and setting}

This study examined 2,245 patients who experienced nontraumatic ICHs while taking anticoagulants (DOAC, 227; warfarin, 2,018) and were urgently hospitalized at 621 Japanese institutions between 1 April 2010 and 31 March 2015.

\section{Design, size, and duration}

This study accessed the DPC database to obtain clinical data including consciousness impairment levels upon admission (as measured with the Japan Coma Scale), surgical removal rates, at-discharge modified Rankin Scale (mRS) scores, and mortality rates.

\section{Primary outcomes}

The primary outcomes were ICH severities, which were assessed based on consciousness impairments or the need for surgical removal, and mortality rates within 1 day, within 7 days, or during hospitalization.

\begin{tabular}{|c|c|c|c|}
\hline Timeframe & $\begin{array}{l}\text { Odds ratio for } \\
\text { mortality }\end{array}$ & $\begin{array}{l}p \\
\text { Value }\end{array}$ & $\begin{array}{l}95 \% \text { confidence } \\
\text { intervals }\end{array}$ \\
\hline $1 \mathrm{~d}$ & 4.06 & $<0.001$ & $1.78-10.99$ \\
\hline $7 d$ & 1.96 & 0.012 & $1.15-3.39$ \\
\hline $\begin{array}{l}\text { During } \\
\text { hospitalization }\end{array}$ & 1.60 & 0.041 & $1.02-2.56$ \\
\hline
\end{tabular}

\section{Main results and the role of chance}

Compared to warfarin-associated ICHs, DOAC-associated ICHs were less likely to cause moderate or severe consciousness impairments at admission ( $39.4 \%$ vs $31.3 \% ; p=0.002)$ or to necessitate surgical removal (9.9\% vs $5.3 \%$; $p=0.024$ ) but were not associated with a lower mean at-discharge $\mathrm{mRS}$ score $(3.50$ vs $3.30 ; p=0.158)$. Furthermore, the patients with DOACassociated ICHs had lower mortality rates within 1 day $(6.5 \%$ vs $2.6 \%$; $p=0.022)$, within 7 days $(18.2 \%$ vs $11.9 \% ; p=0.017)$, and during hospitalization $(25.3 \%$ vs $17.6 \%$; $p=0.011)$.

\section{Bias, confounding, and other reasons for caution}

The DPC database lacks some potentially relevant data, including laboratory data, vital signs data, and end-of-life decisions data.

\section{Generalizability to other populations}

The use of a nationwide database makes this study's results more generalizable than those of previous reports.

\section{Study funding/potential competing interests}

This study was funded by the Japanese government and the Japan Society for the Promotion of Science. Some authors report receiving honoraria, funding, and advisory committee appointments from various pharmaceutical companies. Go to Neurology.org/ $\mathrm{N}$ for full disclosures. 


\section{Neurology}

\section{Comparing intracerebral hemorrhages associated with direct oral anticoagulants or warfarin}

Ryota Kurogi, Kunihiro Nishimura, Michikazu Nakai, et al.

Neurology 2018;90;e1143-e1149 Published Online before print February 28, 2018

DOI 10.1212/WNL.0000000000005207

This information is current as of February 28, 2018

Updated Information \& Services

References

Citations

Subspecialty Collections

Permissions \& Licensing

Reprints including high resolution figures, can be found at: http://n.neurology.org/content/90/13/e1143.full

This article cites 41 articles, 17 of which you can access for free at: http://n.neurology.org/content/90/13/e1143.full\#ref-list-1

This article has been cited by 1 HighWire-hosted articles: http://n.neurology.org/content/90/13/e1143.full\#\#otherarticles

This article, along with others on similar topics, appears in the following collection(s):

All Cerebrovascular disease/Stroke

http://n.neurology.org/cgi/collection/all_cerebrovascular_disease_strok e

All Clinical Neurology

http://n.neurology.org/cgi/collection/all_clinical_neurology

Cardiac

http://n.neurology.org/cgi/collection/cardiac

Intracerebral hemorrhage

http://n.neurology.org/cgi/collection/intracerebral_hemorrhage

Information about reproducing this article in parts (figures,tables) or in its entirety can be found online at:

http://www.neurology.org/about/about_the_journal\#permissions

Information about ordering reprints can be found online:

http://n.neurology.org/subscribers/advertise

Neurology ${ }^{\circledR}$ is the official journal of the American Academy of Neurology. Published continuously since 1951, it is now a weekly with 48 issues per year. Copyright Copyright ( 2018 The Author(s). Published by Wolters Kluwer Health, Inc. on behalf of the American Academy of Neurology.. All rights reserved. Print ISSN: 0028-3878. Online ISSN: 1526-632X.

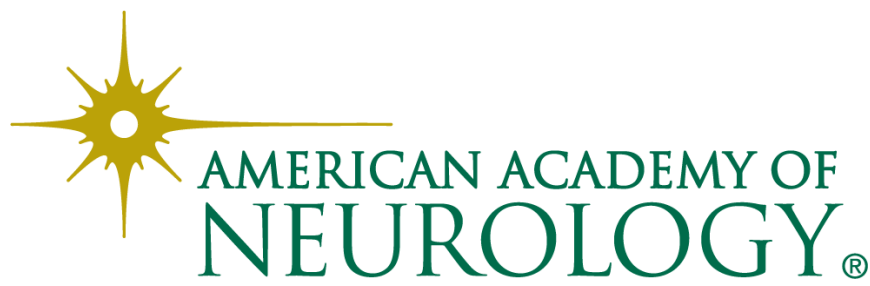

